УАK 316.75:32

ББК 66.05

DOI 10.22394/1682-2358-2019-6-57-65

K.Kb. Sanginov, lecturer at the Department of Political Science, Khujand State University named after Bobojon Gafurov

\section{THE ROLE}

OF THE INFORMATION

SPACE IN THE

FORMATION

\section{OF POLITICAL}

CONSCIOUSNESS

(By the Example

of the Republic

of Tajikistan)

The role and significance of the information space of society in the formation of the corresponding political consciousness of society in the interests of the ruling elite are studied. The essence of the formation of political consciousness and its gradual transformation into an illusory consciousness, as well as the transformation as a tool for manipulating the consciousness of society under a totalitarian regime, is revealed. Open information space under a democratic regime, where political consciousness exists and develops rationally, freely, creating an atmosphere of political pluralism in society is analyzed.

Key words and word-combinations: political consciousness, information space, political regime, totalitarianism, democracy.
К.Х. Сангинов, преподаватель кафедрь политологии Худжандского государственного университета имени Бабаджана Гафурова (email: sk_8888@mail.ru)

РОАЬ ИНФОРМАЦИОННОГО ПРОСТРАНСТВА В ФОРМИРОВАНИИ ПОАИТИЧЕСКОГО СОЗНАНИЯ (на примере Респубцики ТаАжикистан)

Аннотация. Исследуется роль и значимость информационного пространства в формировании политического сознания общества в интересах правящей элиты. Раскрывается суть формирования политического сознания и его постепенное превращение в иллюзорное сознание в качестве инструмента манипуляции сознанием общества при тоталитарном режиме. Анализируется открытое информационное пространство при демократическом режиме, когда политическое сознание существует и развивается рационально, свободно, создавая атмосферу политического плюрализма в обществе.

Ключевые слова и словосочетания: политическое сознание, информационное пространство, политический режим, тоталитаризм, демократия.

B политическом мире, в особенности во взаимоотношениях межау человеком и политической системой общества, а также в тех ими иных его действиях в политическом проџессе, наряду с Аругими 
факторами, определяющими политические отношения, немаловажную роль играет политическое сознание. Этот феномен как Ауховная часть помитической сферы общества, обусловливающий степень вовлеченности, отношение и чувства человека к политике, формируется поА влиянием множества факторов окружающей среды. Политическое сознание - это часть или одна из форм общественного сознания, которая является результатом отражения окружающей среды в контексте воздействия многочисленных факторов. На формирование политического сознания, в частности политическую идеологию и политическую психологию, влияют такие факторы и проџессы, как экономическое состояние, политический режим, а также политическая культура общества в целом как часть того ици иного цивицизационного мира.

Можно констатировать, что содержание политического сознания в одних странах составцяет совокупность более раџионацьных потребностей и ценностей, отвечающих требованиям конкретного субъекта политики как носителя оАного из виАОв политического сознания. В Аругих странах, гАе в сознании масс Аоминирует политическая идеология, одновременно регулируя и контромируя их действия в политических отношениях, политическое сознание более мифологизировано и имлюзорно.

В современном мире заметно возросла значимость политической информации. Исходя из актуальности развития информационных технологий, целью Аанной публикации явцяется определение возможных источников информации в качестве фактора формирования политического сознания. С использованием методов сравнительного анализа и метода историзма ставится задача определения роли и значимости информации в политической истории ХХ в. в разных политических системах, а также вывления значения информационных технологий в современных условиях в проџессе формирования демократических институтов, в частности в Таджикистане.

На формирование и развитие политического сознания особенно влияет доступность или ограниченность информации на общественном уровне. Социальная роль и значимость, а также маневренность информаџии с помощью механизмов Аоступности или ограниченности у субъектов политики в условиях развития информационных технологий в современном мире возрастает. Аля обобщенного восприятия всех каналов СМИ следует использовать понятие «информационное пространство», учитывая особое внимание правящей элиты к СМИ, обусловленное их значимостью в государственной информационной политике. Информационное пространство вкцючает совокупность всех СМИ, их правовой и политический статус, уровень свободы от государственного режима и их отношение с субъектами политики в обществе. Сегодня роль информационного пространства в мире возрастает на фоне крупных социально-политических изменений, связанных с кризисом $\Lambda$ беральных ценностей, волн демократизации, изменения нравственных ценностей в политике и многих Аругих тенденций. В связи с этим возникает вопрос о том, может $\Lambda$ информационное пространство выступать в качестве воздействующего фактора формирования или изменения политического 
сознания участников или субъектов политического процесса в структуре общественных отношений.

По оценкам ученых, «роль и место информации в политической жизни общества определяется отношениями ее с властью, кмючевым, наиболее масштабным и определяюшим явлением политики. Значение силы влияния СМИ на политические процессы, процедуры выработки и принятия решений, создания имиджа властям, политике и политикам постоянно возрастает» [1, с. 398]. Информация с ее значимостью в политике во взаимодействии с такой категорией, как власть, во многих политологических текстах указывается в качестве источника политической вмасти [2, с. 66-67].

Политическое сознание прежде всего представляет собой отражение политической среды, которая существует в стране, имеющей определенные политическую систему, режим, правовые и политическиее нормы, обычаи, традиции и политическую культуру. В политологических источниках политическое сознание часто отождествляется с политической культурой, что основывается на сходстве многих элементов их содержаний. Согласно научному определению, «поА политической культурой понимается исторический и соџиальный опыт национальной или наднациональной общности, которая воздействует на формирование политических ориентаций, политического поведения индивиАов, малых и больших групп» [3, с. 90] .

Таким образом, политическая культура, укоренившаяся в образцах поведения индивида и конкретных соџиальных групп, подвергается изменениям поА воздействием определенных политических событий и акций, что, в свою очередь, трансформирует само содержание политического сознания. Сегодня в политологии утверАилось мнение о своего рода симбиозе политического сознания и политической культуры, позволяющего взаимно использовать в ходе научных исследований их результаты. Так, Н.П. Поливаева утверждает, что «...в выделении основных направлений “Авижения” политического сознания вполне Аогичным и оправданным может выступать динамика и конфигурация современных политических культур» [4, с. 63.] По ее мнению, существуют также типы политического сознания, выявляемые на основании классификации типов политической культуры А.С. Панарина: экономикоцентризм, этноџентризм и соџиоџентризм [5], где, соответственно, и прослеживается тенденџия развития политического сознания в историческом масштабе, представмяюшем его как отражение прошлого, настояшего и буАущего.

Следует учитывать, что формирование и развитие политической культуры в разных исторических эпохах обусловлено уровнем развитости определенных факторов - экономики, общественных отношений, традищий, обычаев, правовых и политических норм, политической системы и Аругих, в совокупности составляющих определенную среду, влияющую на формирование политической культуры общества. Несмотря на нормативные и поведенческие особенности политической культуры, можно утверждать, что политическая культура - это значимые соџиально-политические ценности и нормы, формирующие содержание политического сознания. Укоренив- 
шись в политическом пространстве в силу Аолгого использования обществом или отдельными соџиацьными группами, они диктуют определенный стиль поведения на уровне автоматизма в условиях тех или иных политических событий. Несмотря на взаимосвязь и отождествцение категорий политического сознания и политической культуры, их формирование и развитие оказывается невозможным без коммуникационных каналов в политике, что обеспечивает трансляцию новых политических взглядов в обществе, воспроизводство политической системы, преемственность политической элиты. На взгляА Н.П. Поливаевой, «результат политической коммуникации - это и изменение установок ици поведения под влиянием преАлагаемых коммуникатором стимулов, и требуемая степень согласия участвующих в коммуникации сторон» [6, с. 156].

Политическая коммуникаџия прежде всего обеспечивает реализацию помитической социализаџии общества, результатом которой является формирование и изменение политического сознания. Определенный виА политического сознания индивида, соџиальных групп и общества в конечном итоге проявляется в их поведении: «Сознание и поведение связаны межАу собой социальной информацией. При этом особое значение имеют ее количество и качество. Соответствие поведения сложившимся условиям, таким образом, во многом зависит от сознания, а оно, в свою очередь, - от возможности получения информации и способности пользоваться ею» [7, с. 123].

На формирование политического сознания вцияет степень Аоступности информации о политическом состоянии общества, его отАельных институтов, соџиальных групп и политических элит. Уровень Аоступности информации зависит от степени свободной деятельности среАств массовой информации в обществе. Традиционно под СМИ понимаются газеты, радио, телевидение и Интернет, непосредственно участвующие в процессе политической соџиализаџии индивида и влияющие в конечном итоге на формирование того ици иного вида политического сознания. Но следует отметить, что СМИ всегАа находятся ПоА влиянием Аибо отАецьных государственных органов и институтов, мибо под контролем политических элит, кидера, а в обществах с Аемократическим режимом их Аеятельность регулируется соответствующими нормативно-правовыми актами. Следовательно, СМИ, роль которых весьма значима важна Аля политического воспитания подрастающего поколения и политической соџиализаџии общества, находятся в тесном взаимодействии с государством и Аругими субъектами политических отношений. Аеятельность каналов СМИ и организаџия их взаимодействия с государством вкцючает все методы пропаганды и агитации с вовлечением агентов социализации дия формирования определенных политических взглядов, составцяющих конкретное мировоззрение. Распространение помитической идеологии способствует структурированию информаџионного пространства, где целенаправленно ици хаотично происходит становление политического сознания общества.

Таким образом, Аля выявцения значимости и роли информационного пространства в формировании политического сознания целесообразно использо- 
вать классификацию политического режима, где каждому типу политического режима соответствует определенный тип информационного пространства, характеристики которого определяют отношения СМИ с государстом. Например, при тоталитарном политическом режиме все среАства массовой информации находятся поА государственным контролем, осуществцяемым правящим политическим классом или элитой.

Политическое сознание, формирующее политическую идеологию, нахоАится в центре политической системы тоталитарного государства. Правящая элита оправдывает мегитимность своего статуса в политической системе с первых Аней прихода к власти с помощью каналов СМИ, наА деятельностью которых устанавцивается жесткий контроль в форме цензуры. Основным условием существования тоталитарного режима явцяется использование средств пропаганды и агитаџии Аля формирования соответствующего помитического сознания, поддерживаемого большинством населения а такжке агентами политической социализации и воспитания с целью обеспечения массовой ПодАержки госпоАствУЮщей политической иАеологии. Именно поэтому при тоталитаризме все мировоззрения, теории, конџепции, оппозиџионные политические партии и Авижения, СМИ, не соответствующие идеологии правящей элиты поА Аюбым предлогом или открыто, с помощью угроз и насиция, запрещаются. В условиях тоталитарного общества постепенно формируется можное, имююзорное политическое сознание, где метоАом манипуцяџии сознанием общества искусственно создаются образы справедиивой борьбы за свободу, Аостижения соџиальных успехов, героизма на благо Отечества и Аругие идеологемы офиџиацьной пропаганды. По причине искусственного конструирования политического сознания в тоталитарном обществе Ааже рациональная информация также может негативно вмиять на стабицьность его режима.

А.И. Соловьев утверждает, что «...качественное изменение информационного рынка не может не вовцечь в новые порядки дажке те страны, которые пытаются искусственно изолировать свое информационное пространство от проникновения “чуждых" идей. А разрушение системы единомыслия и есть основная предпосылка крушения тоталитаризма» [8, с. 260]. Примером изменения политической системы может служить история установления фашистской Аиктатуры в Германии в 1933 г. КогАа нацисты открыто уничтожами своих политических противников - коммунистов, а потом и этнических противников, а также их идеологию, митературу, искусство, культуру, они преследовали цель создать однородную соџиальную среАу, соответствующую задаче их Аальнейшего формирования нацистской политической идеологии и политического сознания. Именно по этой причине тотацитарные режкимы, выявляемые по типу политической системы и характеру взаимоотношений с внешней средой считаются закрытой системой.

Соответственно, можно утверждать, что ограниченный Аоступ к информационному пространству при тоталитарных режимах не позволяет политическому сознанию раџионально и свободно формироваться и развиваться, объективно отражая существующую расстановку политических сиц. 
При этом с целью удержания государственной власти и мегитимаџии своих Аействий правящая элита контролирует формирование политического сознание с помощью подчинения информаџионного пространства общества государству.

В закрытом информационном пространстве мюбая идеология, включающая определенные нормы и ценности, неизбежно преврашается в догму. Аюбая информация, в том числе политическая, воздействует на сознание индивида, подвергающегося соџиализации в определенной среде. Напротив, в условиях демократии, в буквальном смысле означающей «народовластие» и характеризующейся открытостью информаџионного пространства, главным усмовием прихода к власти является завоевание доверия народа соџиальными группами ици политической эмитой с целью увеличения чисменности избирателей во время парламентских, президентских и местных выборов.

В современных демократических режимах в проџессе развития информационно-коммуникативных технологий роль и значимость информационного пространства в политике и политических отношениях возрастает. «Без информационного и технического обеспечения функщионирование современных демократических институтов может быть затруднено. ...Обеспечение равного доступа к сетям может способствовать закреплению демократических станАартов на уровнях межличностного и межгруппового общения. Но Аля этого сами средства массовой телекоммуникаџии домжны быть демократически ориентированными» [6, с. 163].

Значимость Интернета среди Аругих СМИ в последнее время заметно возросла. Существует множкество точек зрения по поводу роли Интернета в помитике демократических стран [9]. РяА авторов высказывают негативное отношение к интернет-технологиям: «Аоступность политической информаџии и возможность выражения своего мнения при помощи интернет-технологий не только не делает граждан политически активными, но, вместе с Аругими факторами, способствует снижению интереса к политике» [10, с. 30] .

Согласно иной точке зрения, «...современные политтехнологи в своих действиях больше практически не скованы ни государственными границами, ни законодательством, ни репутационными ограничениями. Огромный объем информации о рядовых пользователях Интернета позволяет сушественно поднять эффективность манипумятивных кампаний, перейти к нишевому и даже точечному воздействию на политическое сознание и поведение гражАан» [11, c. 136] .

Сегодня наблюдается тенденция использования всех каналов СМИ в помитическом процессе со стороны политической элиты и других субъектов помитики. Их действия, как правило, обусловлены тем, что в современном обществе большинство населения так или иначе связано с соџиальными сетями, а часть его пользуется традиционными каналами СМИ - газетами, радио, телевидением. В связи с этим многие субъекты политики дмя реализации своих планов комплексно используют каналы СМИ с целью охвата всех слоев населения. Такой метоА Ф.И. Шарков называет конвергенџией и утверждает, 
что «...реализуемая конвергенция в политической сфере в процессе обмена знаниями, опытом, формами организации политической деятельности, политическими установками и т.п. способствует обобщению политических коммуникативных практик, нацеленных на Аостижение поставленной политической цеми» $[12$, с. 55] .

Безусловно, политический плюрализм, свобода от цензуры всех каналов СМИ в условиях демократических режимах создают соџиальные преАпосылки Аля формирования многообразных типов политического сознания, от правых до мевых. Вместе с тем при демократическом режкиме сохраняется состязательность субъектов политики, ограниченная только избирательным процессом: субъекты политики в процессе борьбы за вмасть с помощью СМИ в рамках норм закона должны завоевать доверие электората [13] .

В настоящее время, несмотря на демократические ценности, во многих

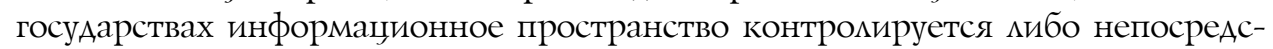
твенно государством, мибо законом. Это вытекает из исторически сложившейся контрольной функщии государства над общественными отношениями, что оправдывает государство как политический институт, даже если оно явцяется Аемократическим.

Аля более полной реализации принципов правового и демократического режкима в обществе во многих государствах, особенно странах СНГ, вкмючая Таджикистан, с целью реализации определенных политических программ и стратегий в процессе политического воспитания в духе патриотизма, наџиональных ценностей, демократических норм и принципов используется контролируемое государством информационное пространство, которое больше всего приобретает идеологическую окраску, и это при том, что в конституциях большинства стран СНГ ни одна идеология не может быть признана государственной.

В Таджикистане проџесс демократизаџии в области СМИ продомжает реализовываться. Увеличивается число государственных, общественных и частных канацов СМИ, что способствует формированию в стране атмосферы политического и идеологического плюрализма в качестве признака Аемократии.

Количество зарегистрированных в Таджикистане СМИ сегодня составмяют 515 газет, журналов и информаџионных агентств, в том числе 330 газет, из числа которых 125 государственные и 205 частные и общественные, 174 журналов (82 государственных и 92 частных), 11 информационных агентств, мишь один из которых является государственным, 66 издательств и 256 типографий [14] .

Аеятельность в Таджикистане СМИ с разными формами собственности и цемями способствует развитию соответствующих видов политического сознания у граждан и направлена на обеспечение качественного предоставления информации. Контроль деятельности СМИ возможен только в рамках норм закона. Таджикские традиционные каналы передачи информации - телевидение, радио и газеты - охватывают большую часть населения, пользоватемями Интернета является в основном молодое поколение страны. С целью 
цифровизации многими СМИ созданы интернет-сайты: «Ховар» - национальное информационное агентство Таджикистана; «ТВ Варзиш» - спортивный телеканал; "Avesta» - информационное агентство; «Чумхурият» ежедневная газета; «Темевизиони Точикистон» - телеканал; «Независимое мнение» - агрегатор новостей ТаАжикистана; «Садои марАум» - ежедневная газета; «Фараж» - еженедельная газета; «Комитет по телевидению и радиовещанию при Правительстве Республики Таджикистан»; «Национальная ассоџиация независимых средств массовой информации ТаАжикистана»; «Asia-Plus» - радиостанџия; Республиканский пресс-центр «Иттилоот ва муошират»; «ENT.TJ» - агрегатор экономических новостей Таджикистана; «ENT.TJ» - агрегатор экономических новостей Таджикистана; «Ватан» - радиостанция [15].

Вместе с тем, несмотря на возрастающую роль социальных сетей, в Таджикистане время от времени наблюдается временное блокирование некоторых социальных сетей (Facebook и ОАнокмассники, Instagram и ВКонтакте) с цемью ограничения молодых мюдей, не сформировавших четкие политические, идеологические и религиозные взгляды, от вербовки в различные террористические и экстремистские организации.

Таким образом, открытость информационного пространства при демократическом режиме дает возможность услышать проблемы и системного, и кичного, и группового характера, которые отражаются в общественном мнении населения. В условиях демократии субъектам политики приходится обращать внимание не только на политические идеологии и взгляы соџиальных групп и общества в целом, но и на политическую психологию, отражающую повсеАневные проблемы и потребности населения.

Вследствие этого роль политического сознания в открытом современном информационном пространстве возрастает, так как в сложившихся условиях отношение кажАого индивида и соџиальных групп к политике напрямую зависит от контроля их политической психологии и скорости распространения той или иной информаџии с помощью СМИ. При этом в неконтролируемых СМИ объектом манипуляции может стать политическая психология насемения, негативно формирующая содержание политического сознания масс, соџиальных групп и индивидов с целью вовлечения их в деятельность экстремистских организаций.

В контексте соотнесения информационного пространства с типами помитического режима наблюдается их соответствие по открытости и закрытости, что и формирует характер информационного пространства. Следовательно, политический режким явцяется особым стилем, методом отношения власти и общества. Например, при тоталитаризме, характерными чертами которого являются ограничение и свободы слова, установцение жесткой цензуры, запрет инокомыслия и распространение идеологии господствующего класса ици элиты с использованием всех средств и каналов массовой информации, создается атмосфера закрытого информационного пространства и соответствующего политического сознания с Аоминированием политической иАеологии. 
Аемократический режим характеризуется такими особенностями, как политический плюрализм, свобода слова, печати, СМИ, наличие многопартийности. При этом существуют условия и возможности каждого субъекта политики и каждого гражданина свободно выбирать и развивать ту или иную политическую иАеологию или взгляды, создавая условия Аля открытого информационного пространства в обшестве.

Итак, информационное пространство весьма значимо дмя формирования определенного типа политического сознания в обществе, обусловленного прежАе всего степенью его закрытости или открытости, зависящей от политического режима.

В условиях трансформаџии политической системы современного ТаАжикистана государство вынуждено осуществцять законодательный контроль над СМИ. Аанная мера является единственно правильной в настоящее время, когда в обществе господствует идеологический «вакуум» и быстро набирают силу идеологии религиозного экстремизма в мире и странах Центральной Азии. Современное информационное пространство ТаАжикистана становится полем быстрого формирования общественного и политического сознания населения, что соответствует требованиям политического и идеологического плюрализма в качестве неотъемлемой особенности демократического строя.

\section{Библиографический список}

1. Политология: курс лекций / под ред. М.Н. Марченко. 4-е изд., перераб. и доп. М., 2003.

2. Политология / Мельвиль А.Ю. [и др.]. М, 2007.

3. Усикова Л.Ф. Политическая культура // Вестник МГГУ им. М.А. Шолохова. 2010. № 1. C. $90-101$.

4. Поливаева Н.П. Об эволюции политического сознания в современном мире // Власть. 2008. № 6. С. $63-67$.

5. Панарин А.С. Политология. М., 2003.

6. Шарков Ф.И. Политическое сознание - политическая практика - политическая коммуникация // PolitBook. 2014. № 1. C. 153-165.

7. Поливаева Н.П. Особенности теоретико-эмпирического осмысления политического сознания россиян // Власть. 2013. № 8. С. 120-123.

8. Соловьев А.И. Политология: Политическая теория, политические технологии. М., 2009.

9. Акаев Д.В. Интернет-сообщества: место и роль в политическом процессе социума: автореф. дис. .... канд. социол. наук. Саратов, 2009.

10. Балашов А.Н., Бочанов М.А. Интернет-технологии как фактор развития политической активности граждан: тренды и противоречия // PolitBook. 2017. № 2. С. 20-34.

11. Маслова A.A. Интернет как новый канал манипуляторного воздействия на массовое политическое сознание. Тамбов, 2014. № 5 (43). Ч. 2. С. 134-137.

12. Шарков Ф.И. Медиаконвергенция пространства политической сферы общества // PolitBook. 2017. № 2. C. 47-57.

13. Акаев Д.В. Социально-политическая активность участников Интернет-сообществ // Среднерусский вестник общественных наук. 2014. № 4 (34). С. 45-48.

14. Национальная ассоциация независимых СМИ Таджикистана (HAHCMUT). URL: http://nansmit.tj

15. URL: https://xp.tj/category/media/ 